Carlos Valenzuela

Estudiante Universidad Pedagógica Nacional

\title{
¿PARA QUÉ HABLAN LOS ESTUDIANTES EN EL AULA DE CLASES?
}

La idea alrededor de la cual giran mis intenciones de análisis en el marco de este escrito, se orienta hacia el tema de "para qué hablan los estudiantes en el aula de clases". Por supuesto, es éste un tema muy amplio que delimitaré mediante el planteamiento de una categoría de construcción progresiva que, en la medida de lo posible, dará cuenta de aspectos muy puntuales en relación con el discurso oral de los estudiantes y las intenciones de participación que en él subyacen como indicadores de procesos de apropiación de los contenidos académicos o simple adecuación a la lógica de la actividad en clase.

En primera instancia, describiré brevemente la estructura del trabajo en general $y$, en segundo lugar, aludiré a las razones que me abocaron a elegir el discurso de los estudiantes, dentro de la clase, como objeto de observación y análisis.

Este ensayo se divide en tres partes: la primera hace referencia a la categoría de interpretación y a los referentes teóricos que orientaron la dirección conceptual de este escrito; la segunda aborda el análisis concreto de los registros en relación con la participación oral de los estudiantes en clase; y la tercera y última revela las conclusiones a las que dio lugar el análisis mencionado.
Metodológicamente, este análisis parte, en primer lugar, de elementos relacionados con la etnografía, en la medida en que recurrí a ciertas técnicas etnográficas para recolectar la información y, en segundo lugar, de aspectos relativos al enfoque de "análisis del discurso", el cual, fortaleció y respaldó el análisis del que fueron objeto los registros tomados en el aula. Seleccióné como marco referencial de interpretación un registro de una clase de español de 45 minutos, dirigida por una maestra del área. La clase se realizó en un colegio del municipio de Soacha Cundinamarca.

\section{JUSTIFICACIÓN}

La comunicación que en una clase se establece entre docente y estudiantes es analizable desde un conjunto amplio de perspectivas que pueden ser abordadas desde diversas disciplinas. La perspectiva que en este caso atrae mi atención es de carácter pedagógico en la medida en que, el discurso de los estudiantes en el aula está sujeto a unas didácticas, a unas reglas, a unas prácticas pedagógicas que vehiculan las dinámicas de enseñanza- aprendizaje prescritas por el maestro. Es en este ambiente pedagógico donde tiene lugar la participación oral de los estudiantes, y es sobre él 
y su influencia en las intenciones de participación oral de éstos últimos donde empezará mi reflexión, la cual, me conduce desde ya a formular la siguiente pregunta desencadenante: ¿Las intenciones de participación oral de los estudiantes de dónde se derivan? ¿Acaso, de su curiosidad por los contenidos académicos e interés de participar activamente en la estructuración de la clase 0 , se condensan en el propósito forzoso de culminar cuanto antes el rito de clase en el que están involucrados? Estos interrogantes demandan una mirada crítica alrededor de la figura del estudiante como agente partícipe o receptor pasivo en lo que respecta a la realización de las dinámicas de clase en las cuales se halla. Por consiguiente, analizar y discutir los cuestionamientos relativos a la naturaleza de las intenciones que conducen a los estudiantes a participar oralmente en clase con el fin de apropiarse del contenido académico o con la idea de ajustarse a la lógica de la actividad del maestro, son las razones que justifican y respaldan el origen de este trabajo, el cual rastrea, a través de un análisis del discurso de los estudiantes, los fines que éstos tienen o manifiestan al hablar en el aula.

Con base en esta perspectiva teórica, trazo una categoría que permita describir las intenciones de participación a las que se circunscriben, por lo general, los estudiantes en el aula de clases. La elección de esta categoría: intenciones de participación, surge a partir de un eje de clasificación que gira entorno a la pregunta ¿para qué hablan los estudiantes en el aula de cla-

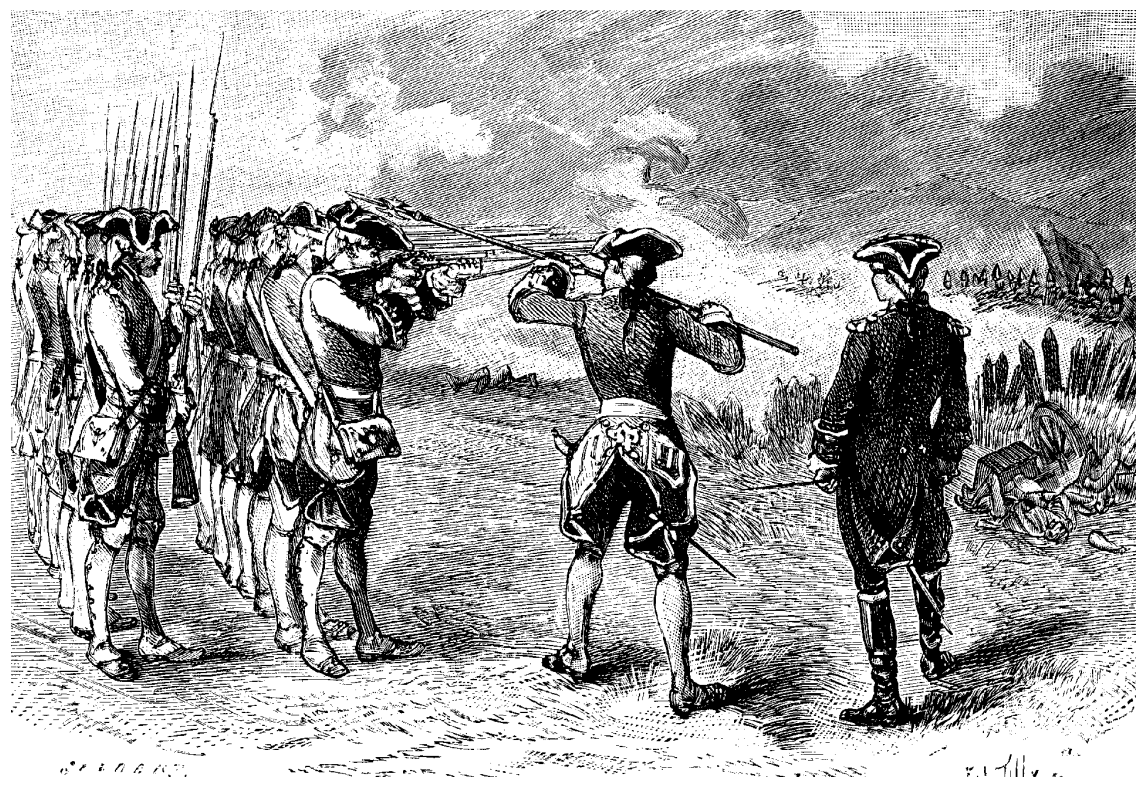

ses? Tema cuyo radio de análisis, espero reducir mediante el planteamiento de esta categoría puntual, con la que busco evitar el desbordamiento del estudio.

\section{CATEGORÍA DE ANÁLISIS}

\section{Intenciones de participación:}

Entendida como la finalidad o la intencionalidad que el estudiante revela, al participar oralmente en el transcurso de la clase. Se hace visible aquí un compás de posibilidades grande alrededor de las posibles intenciones que persuadirían a un estudiante a hablar en clase, entre ellas, señalo las siguientes cuya construcción realicé a partir de la reflexión a la que dieron lugar mis observaciones en el aula:

1. La intención de insertarse a la lógica de la actividad que el maestro propone en su clase para acceder al "juego" de reglas y normas que regula el espacio del aula.

2. La intención de obtener la aquiescencia del maestro con el fin de arribar a mejores notas pese a no dominar el tema.

3. La intención de confrontar lo expuesto por el maestro dando muestras simultáneamente de que hay apropiación del contenido académico.

\section{HORIZONTES O REFERENTES CONCEPTUALES DE INTERPRETACIÓN}

Propongo ver y entender el escenario del aula desde una perspectiva compleja, es decir, desde una perspectiva que revele su configuración en red, su condición de tejido; trama en la cual, maestros y alumnos se insertan y establecen relaciones de orden social, cultural y político cotidianamente en el aula, espacio institucionalizado por excelencia. 
La perspectiva compleja que sugiero emplear, pienso, nos brinda una óptica de análisis diferente, no mejor, del espacio escolar, respecto de aquella unilateral tipo diagnóstico, cuyo énfasis se concentra sólo en los resultados, y no en los procesos, que arroja la práctica pedagógica del maestro y el rendimiento académico de los estudiantes en la escuela, puesto que, al advertir o aprehender, mediante tal perspectiva compleja, el origen y la naturaleza de las relaciones que se tejen en el aula: en dónde convergen, en qué divergen, cómo se producen y qué acarrean, la lectura que se hace de dicho espacio no es maniquea ni simplista, dado que intenta dar cuenta de las razones alrededor de las cuales se constituyen las dinámicas, por ejemplo, de participación, tan importantes en la escuela, y no de "cómo debería ser la educación, los maestros y los estudiantes".

Por consiguiente, al ser la "relación”, en este caso, el fenómeno a partir del cual procedemos a interiorizar el mundo del aula, complejizar dicho espacio, me parece prioritario. Veamos.

El estudiante, al ingresar a la escuela, incrementa indiscutiblemente su saber cotidiano entendido como, según Heller, "la suma de nuestros conocimientos sobre la realidad que utilizamos de un modo efectivo en la vida cotidiana del modo más heterogéneo" Dicho saber, el estudiante lo somete a un proceso de selección, donde elige aquello que llama su atención en relación con el am-

${ }^{1}$ Heller, A. Sociología de la vida cotidiana. Madrid: Península. 1977, pág. 317. biente social donde se desenvuelve temporalmente, en este caso, la escuela.

Digamos que interactúa, conoce y reconoce su ambiente, su lenguaje, sus reglas y, a su modo, procura adecuarse a estos elementos, contrarrestando de manera permanente aquello que sabe con lo que paulatinamente conoce. Establece un paralelo entre aquello que corresponde al contenido de su saber cotidiano y aquello que corresponde al contenido académico de la escuela. En esta relación: la escuela por una parte y su mundo por otro, no sólo entran en juego los contenidos académicos propios del currículo escolar y el acervo de saberes cotidianos propios del estudiante, también inciden las formas, los medios, los vínculos que posibilitan y propician el entrecruzamiento, el acoplamiento de dichos saberes; nexos que nacen, entre otras cosas, a partir de la interiorización que los estudiantes hacen de "los sistemas de uso y de los sistemas de expectativas"2 de su escuela, es decir, de los códigos y reglas de interacción a las que ha dado lugar su propia relación con los objetos y sujetos que en la escuela los rodean. Así, cuando el estudiante logra interiorizar y aceptar dichas reglas, en otras palabras, cuando se familiariza con el escenario social particular de su institución, con sus actores, con sus parlamentos, sus usos, sus costumbres, en fin, en términos de Bourdieu, con el "campo"3 o espacio de juego que

\footnotetext{
${ }^{2}$ lbid., pág. 21.

${ }^{3}$ Bourdieu, Pierre. Sociología y cultura. México D.F.: Grijalbo, 1984, pág. 157.
}

constituye la escuela, reviste de significado todo aquello que lo circunda, incluyendo los contenidos académicos. Pero, ¿cómo se relaciona con dichos contenidos? ¿Por qué razones? Las razones que los motivan por apropiarse de dichos contenidos, constituyen los mencionados vínculos o nexos que propician la integración efectiva o no del contenido académico de la escuela en el saber cotidiano del estudiante; razones muy heterogéneas relacionadas con las intenciones que el estudiante revela en el momento de apropiarse 0 no del contenido académico. Múltiples podrían ser estas razones que inducirían a los estudiantes a querer integrar los contenidos académicos de la clase a su saber cotidiano, suponiendo, por supuesto, que tal intención de integración, subyace en ellos. Cuando dicho propósito de conjugar lo académico de los contenidos de la escuela con lo cotidiano de los idearios de los estudiantes, no existe, es posible que ello no se haga evidente en el transcurso de la clase, dado que los estudiantes, pese a no interesarse por la apropiación de los contenidos que el maestro expone, optan por decodificar, descifrar y adecuarse a la lógica da la actividad que éste propone, es decir, participan y responden en la clase, no a razón de su interés por querer aprender, sino en función del cumplimiento de las reglas, condiciones, objetivos y expectativas que manifiesta el profesor con respecto al desarrollo de su clase. En otras palabras, a lo que se enfrentarían los alumnos posiblemente sería al dispositivo de poder que esgrime la escuela en relación con su tarea institucional de eva- 
luar, reprobar o aprobar al estudiantado, el cual, aparentaría integrar el contenido académico a su saber cotidiano para cumplir con las políticas de la escuela y no porque deseara, a partir de sus expectativas con respecto a lo que quisiera aprender, sinceramente hacerlo.

El que los alumnos se sumen a la idea de aprobar y obtener resultados satisfactorios en sus evaluaciones, tiene su razón de ser ya que "el discurso educativo tiende a presentar una escuela homogénea, representante fiel de la cultura de la sociedad, que paulatinamente excluye a todos aquellos estudiantes que no cuentan con las competencias culturales que presupone el trabajo escolar"4 esto no sólo implica un desplazamiento en la instancia de la escuela sino también en otros ámbitos como el de la familia, en el cual, se enjuicia infundadamente al joven estudiante por su fracaso escolar sin considerar ninguna otra variable aparte de la no aprobación del curso, pues lo que los padres desean es que su hijo apruebe a como de lugar. Veamos el siguiente aparte de una entrevista hecha a la maestra de la clase registrada para este análisis:

ENTREVISTADOR: ¿Cómo le fue en la reunión de hoy? (Entrega de boletines con padres de familia).

PROFESORA: ...seguramente los alumnos ya le habían dicho a los padres sobre los resultados

\footnotetext{
${ }_{4}^{4}$ Álvarez, A.; Rockwell, E. y otros. Hacia un currículo cultural. Rockwell, E. Cap. 1 : La dinámica cultural en la escuela. España: Infancia y Aprendizaje. 1997, pág. 35.
}

finales y, pues ellos ya venían preparados, el problema es que muchas veces el alumno no es capaz de decirle la realidad al padre y viene y choca contra uno... a raíz de eso pues me he ganado cantidades de problemas porque los padres de familia no aceptan, aquí la cultura del medio es que los niños tienen que pasar, pasar como sea...

A partir de esta situación conflictiva, atravesada por otras variables de índole cultural, los jóvenes, como afirma Rokwell, "se apropian de manera selectiva de ciertos conocimientos ofrecidos y crean estrategias para sobrevivir como estudiantes" 5 .

Ahora bien, aludiendo al tema de la relación entre el mundo cotidiano del estudiante y el contenido académico de la escuela, al que veníamos haciendo referencia en líneas anteriores, lo retomo afirmando que las razones que impelen a los alumnos a incorporar los contenidos académicos a su saber cotidiano, se desprenden de muy diversas vertientes, una de ellas, por ejemplo, corresponde a la de confrontar lo expuesto por el maestro evidenciando su intención de querer apropiarse del contenido académico que se expone, razón que propiciaría la participación del estudiante en la dinámica de la clase y no, como si posiblemente lo generaría la situación de conflicto que describí en el párrafo anterior al referirme a la incidencia de la evaluación en relación con el fracaso escolar, una actitud receptora pasiva por medio de la cual, el alumno busca

\footnotetext{
${ }^{5}$ Ibid., pág. 32.
}

ajustarse a la lógica de la actividad académica con el propósito de aprobar la clase a como de lugar.

Hasta este punto, con base en las reflexiones a las que ha dado origen el análisis, he hablado someramente acerca de las intenciones de participación que, a mi modo de ver, subyacen en los estudiantes al hablar en clase. Ahora, con base en algunos otros apartes del registro seleccionado, procederé a ilustrar con mayor minuciosidad la categoría de análisis que empleé, refiriéndome con especificidad a las intenciones que tiene el estudiante de: Insertarse a la lógica de la actividad prescrita por el maestro, obtener mejores notas en pos de la sobre vivencia académica y confrontar lo expuesto por el maestro evidenciando previa intención de querer apropiarse del contenido académico.

La clase de español se inicia con la intervención de la maestra quien, dirigiéndose a sus estudiantes, define el objeto y propósito de la clase: "trabajar ... la acentuación de las palabras y las divisiones según su acentuación". Esta apertura y el posterior desarrollo de la clase determina un tipo de interacción comunicativa maestro-alumno específica, entendiendo comunicación como "un proceso constante de superación de incertidumbres"6, que corresponde al tipo "lección"7, en donde la maestra planea y ex-

\footnotetext{
${ }^{6}$ Robison. Citado por Valsiner. Enseñanza, aprendizaje y discurso en el aula. Madrid: Aprendizaje S.L. 1996, pág. 136.

${ }^{7}$ Ver Calvo, Beatriz; Ballesteros, G. y otros. Nuevos paradigmas, compromisos renovados. Cap. El análisis del discurso en el
} 
plicita los fines específicos de su clase y determina el procedimiento a seguir para cumplir su objetivo. Veamos el siguiente aparte.

Clase de la profesora $(P)$, sexto grado

1) $P:$ Niños vamos a trabajar entonces la acentuación de las palabras y las divisiones según su acentuación ¿no? [mirando las carteleras que los niños trajeron y están pegando en el tablero] Ah, el acento prosódico... pero yo les dije que no escribieran conceptos sino ejemplos... Como ustedes habían hecho el taller la vez pasada ustedes saben que hoy vamos a mirar que es lo que hemos aprendido de los diferentes conceptos... a ver, yo quiero que un niño me diga... como yo les dije niños en cartelera no me hicieran conceptos... uno de los niños que investigó sobre acento ¿qué es acento prosódico? Y ¿qué es acento ortográfico? A ver... no aprendieron la diferencia entre el uno y el otro, es muy sencillo.

2) Alumno: En el acento prosódico tiene una sílaba.

3) P: Tónica... ¿qué quiere decir tónica? A ver.

4) Alumno: Que lleva más fuerza [vacilando].

5) P: la sílaba tónica entonces es una mayor fuerza que hago en una sílaba...

De entrada, la dinámica de interacción comunicativa, tipo lec-

salón de clases. Klingler y Romero. México, Universidad Autónoma de Ciudad Juárez, 1998, pág. 166.

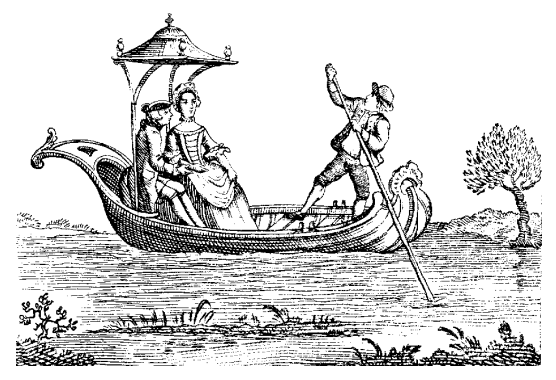

ción, se establece, es decir, la maestra es quien da las instrucciones a sus estudiantes respecto del tema a tratar, además, determina aquello de lo que se hablará:

1) "Ah el acento prosódico... pero yo les dije que no escribieran conceptos sino ejemplos... ustedes saben que hoy vamos a mirar que es lo que hemos aprendido de los diferentes conceptos".

Parece ser, según la línea anterior, que no existe correspondencia entre lo que la maestra propone y los estudiantes hacen (... pero yo les dije que no escribieran conceptos sino ejemplos...) ello evidencia fallas en los procesos de comunicación básicos, en donde se espera que lo que la maestra emite sea captado por los estudiantes, sin embargo, pese a la divergencia de opiniones entre maestro y alumnos en materia de mensajes, éstos tratan de "adecuarse a la lógica de trabajo que plantea seguidamen-

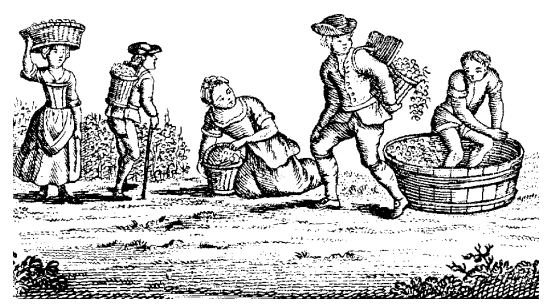

te la maestra" lo que los conduce finalmente a hablar para repetir de modo autómata lo que la maestra expone en el transcurso de la clase con el fin de acceder a su discurso y a su rito didáctico.

Vale la pena subrayar que, las intervenciones de los estudiantes, por cierto, tímidas y muy periféricas, no son consideradas por la maestra dado que ella demanda un tipo de respuesta específica:

6) P: "¿qué es acento prosódico? Y ¿qué es acento ortográfico? A ver... no aprendieron la diferencia entre el uno y el otro, es muy sencillo.

7) Alumno: En el acento prosódico tiene una sílaba.

8) P: Tónica... ¿qué quiere decir tónica? A ver.

El que la maestra no considere las respuestas emitidas por los estudiantes, lo cual es muy regular en el transcurso de la clase, puede justificar el hecho de que los alumnos le resten importancia a su participación, ya que, pueden tener la idea de que, lo que dicen, no es escuchado y tomado en cuenta, a menos que sea lo mismo que el maestro dijo, de allí que opten la mayoría de las veces por repetir. Este estado de cosas obstaculiza la posibilidad que los estudiantes tendrían de confrontar lo que la maestra expresa en la clase, sin el temor de que, lo que manifiestan, no coincida con lo que ella piensa o dice. El discurso de los estudiantes se circunscribe al discurso del aula, establecido a priori por el maestro, hablan para acceder discursivamente al espacio cifrado del aula dado que 
"un aula es un lugar especial para el desarrollo de un conjunto selectivo de actividades educativas" ${ }^{\prime \prime}$. Esta fuerte, en términos de Bernstein, "clasificación" entre maestros, alumnos, discursos, etc., en el aula, define y legitima el grado de participación al que podrían arribar los estudiantes, y ello no necesariamente lo explicita el maestro en el desarrollo de su clase, de hecho, los alumnos ya han interiorizado esas reglas, al punto de no concebir, por ningún motivo, la idea de confrontar el discurso predominante, pues su rol de alumno, el que han interiorizado por causa de aquel imaginario en el que, el maestro es el poseedor del saber y el alumno el que aprende, les sería ambiguo en el caso de no adecuarse a la lógica de la actividad en clase.

Hasta el momento, sólo he mencionado los factores, en términos de estructuras de poder en el aula, que, a mi modo de ver, propician la intención que tienen los estudiantes de insertarse a la dinámica didáctica prescrita por la maestra con el propósito de "pasar" la clase de turno. Ahora, observemos este mismo hecho de intenciones de participación, pero desde la relación que se establece entre el contenido académico de la escuela y los estudiantes.

Veamos el siguiente ejemplo:

\footnotetext{
${ }^{8}$ Coll, César y Derek, Edwards. Enseñanza, aprendizaje y discurso en el aula. Cap. 2: Indeterminación restringida en los procesos del discurso, Jaan Valsiner. Madrid: Aprendizaje S.L.,1996, pág. 27.

${ }^{9}$ Bernstein, B. La estructura del discurso pedagógico. Ediciones Morata,1994.
}

98) P: Bueno, entonces las agudas son aquellas cuyo... cuyo acento se marca la tilde cuando termina en vocal o en consonante "ene" o...

99) Alumnos: "ese".

100) P: Además que el acento lo tiene en la última...

101) Alumnos: Sílaba.

102) $P$ : Bien, vamos con las graves, ¿qué es graves? A ver...

103) Alumnos: Son aquellas que llevan el acento en la penúltima sílaba.

104) P: En la penúltima, para poder tener graves debemos tener mínimo dos...

105) Alumnos: sílabas.

106) P: Vamos entonces con ejemplo ¿cuándo le marcamos tilde a las graves? A ver ¿cuándo le marcamos tilde a las graves?... ¿tú hiciste la investigación de graves? ¿Cuándo? [El niño no contesta] o bueno ¿cuándo le marcamos a las graves? [Dirigiéndose a otro niño]. 107) Alumno: Se tilda cuando terminan en vocal a, e, i, o, u o en las consonantes "ene" o "ese". 108) Alumnos: Noo... cuando no termina [en coro].

109) P: Pero entonces volvemos a las agudas... ahora entonces las agudas, perdón, las graves se tildan todo lo contrario, no se tildan cuando terminan en... 110) Alumnos: [En coro] vocal.

Es evidente la total ausencia de confrontación en el ejemplo anterior, al igual que es muy visible la constante repetición en la que incurren los estudiantes al responderle a la maestra [Líneas 99, $101,105]$. Por supuesto, ello tiene su razón de ser, vemos como la maestra emplea un discurso especializado, comporta mentalizado, inaccesible de cierta manera para los estudiantes quie- nes no manejan dicho lenguaje, ello, por supuesto, impide que los estudiantes, desde su discurso propio, hablen para confrontar lo expuesto por el docente y así, hacer visible que se han apropiado de dicho contenido pues, como apunta Roger Chartier "la apropiación siempre transforma, reformula y excede lo que recibe"10. No obstante, los estudiantes no dejan de prestar atención a lo dicho por la maestra, puesto que lo precisan para, al hablar, poder repetir, así sea de manera mecánica e irreflexiva (línea 107) lo que la maestra expone en la clase. En última instancia, su fin consiste una vez más en adecuarse al rito propuesto por el docente de "inicio, respuesta y evaluación"11 al dar la lección. Veamos:

111) P: Estas sí [indicando en el tablero] estas no, todo lo contrario. Las graves entonces las tildamos cuando no terminan, quiere decir... en vez de decir que terminan, vamos a decir lo contrario, lo positivo cuando terminan en consonantes diferentes a "ene" o...

112) Alumnos: "ese"

113) P: O que no sea vocal [una alumna levanta la mano] tú, ¿qué quieres decir?

114) Alumna: Que se podía cárcel o lápiz.

115) P: Cárcel ¿en qué termino? 116) Alumnos: en "ele".

\footnotetext{
${ }^{10}$ Ver Álvarez, A. Rockwell, E y otros. Hacia un currículo cultural. Rockwell, E. Cap. 1: La dinámica cultural en la escuela. España: Infancia y Aprendizaje, 1997, pág. 31.

${ }^{11}$ Modelo instruccional de Mehan, $1979 \mathrm{Ci}$ tado por Klinger y Romero. Nuevos paradigmas; compromisos renovados. México: Universidad Autónoma de Juárez.1998, pág. 164.
} 


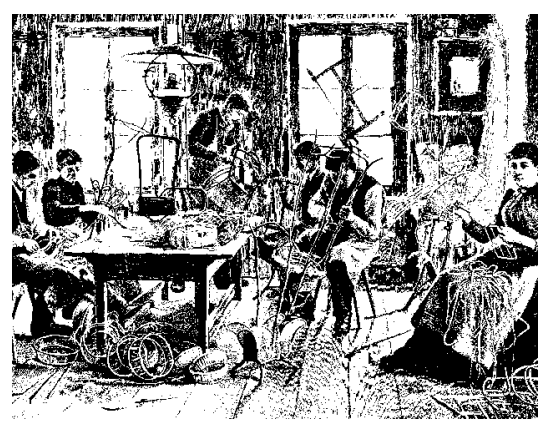

Por otro lado, cabe señalar que no hay apropiación en relación específica con el contenido en juego, prueba de ello es la línea 107 donde el estudiante reitera lo que en un momento dado escuchó en el transcurso de la clase, sin percatarse de que el tema del cual se habla es sobre las graves y no sobre las agudas. Ello, por supuesto no obsta que los niños, en otro sentido, se apropien de otros elementos que igual convergen en la clase, derivados no tanto de la relación que establecen con el contenido académico sino, más bien, producto de las relaciones sociales que entablan con sus pares y el maestro. Recordemos que "la interacción recíproca para el logro de la comunicación involucra el mantenimiento de la armonía entre los interlocutores, porque la negociación de significados es también negociación de relaciones sociales"12 en esa medida, los estudiantes que no se apropian de los contenidos académicos, buscan alternativas de pervivencia escolar distintas a las prescritas por la nota o la clase, "se enfrentan continuamente a ta-

12 Ghio,E.; Hechim, M.; Menéndez, M. y otros. Decir, hacer y enseñar. Argentina: Universidad Nacional del Litoral. 1997, pág. 77. reas nuevas, deben aprender nuevos sistemas de usos, adecuarse a nuevas costumbres... viven al mismo tiempo entre exigencias diametralmente opuestas, por lo que deben elaborar modelos de comportamiento paralelos y alternativos"13 así pueden, en situaciones conflictivas, como afirma Erickson, o "recurrir a la única arma que tienen, la posibilidad de resistirse a aprender lo que la escuela quiere que aprendan, proceso que los condena al fracaso escolar"14 $\mathrm{o}$ adherirse, como en nuestro caso, a los requerimientos didácticos del docente, precisando más su simpatía y aceptación que la apropiación del contenido académico como tal. El aula supera entonces su condición de entorno físico y se convierte en "espacio social"15.

Veamos un ejemplo:

210) P: ... Vamos entonces a hacer un cuadro de clasificación, vamos a hacer lo siguiente.

211) Alumno: ¿en cual cuaderno?

213) P: Ah en el de apuntes, perdón, en el de ejercicios... vamos a hacer un ejercicio con base en un cuadro historial... felicito a los niños ahí sentaditos que hicieron las carteleras.

214) Alumnos: Gracias.

\footnotetext{
${ }^{13}$ Heller, A. Sociología de la vida cotidiana. Madrid: Península. 1977, pág. 20.

${ }^{14}$ Ver Álvarez, A.; Rockwell, E. y otros. Hacia un currículo cultural. Rockwell, E. Cap. 1: La dinámica cultural en la escuela. España: Infancia y Aprendizaje. 1997, pág. 26.

${ }_{15}$ Ghio,E.; Hechim, M.; Menendez, M. y otros. Decir, hacer y enseñar. Argentina: Universidad Nacional del Litoral. 1997, pág. 75.
}

215) P: ... yo les voy a dar a ustedes una lista de palabras y ustedes van a hacer lo siguiente, entonces a ver...

215) Alumna: profe ¿así? [la profesora no le responde].

Los estudiantes, a pesar de no favorecer una apropiación efectiva de los contenidos escolares, sí dan muestras, a través de sus respuestas y preguntas, de apropiarse de la dinámica social de la actividad [Línea 114, 211, 214 y 215] Rockwell y Gálvez nos ilustran al respecto:

"a través de las respuestas de los niños notamos, por ejemplo, que los alumnos atienden simultáneamente dos niveles, uno representado por la lógica del contenido, del razonamiento que presenta la maestra, y el otro constituido por la "lógica" de la interacción misma en que la maestra fija reglas y rituales de participación, evalúa respuestas, da pistas, etc." 16 .

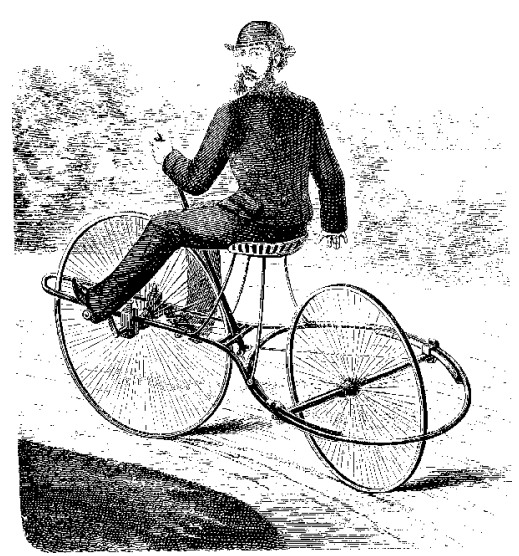

\footnotetext{
${ }^{16}$ Rockwell, E. y Galvez, G. "Formas de transmisión del conocimiento científico, un análisis cualitativo". Educación: Revista del Consejo Nacional Técnico de la Educación, No. 42. México, 1982, págs. 97-139.
} 
Así pues, vemos cómo los estudiantes suman su participación a lo que la maestra expone y exige, saben que, más que apropiarse del contenido que explicita la maestra, lo que deben hacer es manipularlo temporalmente, lo que dure la clase, para salir ilesos, académicamente hablando, a descanso. Responden más al ritmo que la maestra impone en su clase que al interés que podría suscitarles el tema tratado. Esta actitud competitiva que asumen los alumnos frente a sus compañeros a causa de las relaciones de poder que se despliegan a partir de los roles preestablecidos alrededor del proceso enseñanza-aprendizaje (quien sabe y quien no sabe):

143) P: Bueno, ustedes me dicen ¿por qué marcaron tildes en las siguientes palabras? [Enuncia una serie de palabras como martes, césped, frágil, etc., finaliza el ejercicio con la palabra álbum]

158) P.: "Álbum".

159) Alumnos: [en desorden] noo... sii...

160) Alumno: [Señalando al compañero] usted dijo que sí.

Se desprende también, entre otras cosas, de la imagen que de la maestra se han hecho los alumnos a causa de los comentarios que giran en torno a su desempeño en la escuela:

Profesora: ... ha habido mucha gente que me dice que "usted choca, la educación que usted recibió fue de mucha exigencia y usted quiere que todos los estudiantes lleven esa línea"... yo tengo una fama acá terrible, cuando por ejemplo yo en el fondo y por encima y en mi piel soy muy sensible, si alguien quiere a los niños soy yo, pero porque los quiero les exijo, y porque así me educaron y así me forme...

Una imagen de exigencia. Veamos otro aparte de la entrevista hecha a la maestra en cuestión para ilustrar lo expuesto:

Entrevistador: Usted me contaba que tenía miedo.

Profesora: ... yo me considero muy valiente aquí en el colegio, me enfrento a lo que sea y soy muy vertical en mis cosas, a raíz de eso pues me he ganado cantidades de problemas porque los padres de familia no aceptan, aquí la cultura del medio es que los niños tienen que pasar, pasar como sea, no calidad, y yo tengo la idea, la idea mía o la filosofía mía es que hay que exigir para que haya calidad, que por muy pobres que sean los niños hay que enseñarlos a que ellos sean la excelencia, que pidan excelencia, que trabajen con excelencia y que superen esas dificultades y ese medio en el que están... Porque después de que he hecho una reflexión y un análisis de los resultados es que yo doy los resultados, y soy también, trato de ser muy justa si ha habido esfuerzo y ha habido dificultad, pues yo tengo en cuenta, pero nunca tengo en cuenta la situación de un muchacho por-

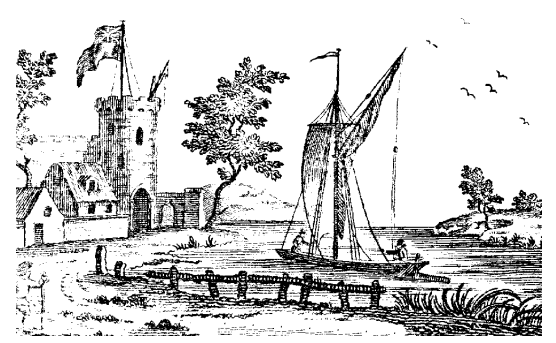

que no quiera superarse... Ha habido mucha gente que me dice que "usted choca, la educación que usted recibió fue de mucha exigencia y usted quiere que todos los estudiantes lleven esa línea".

Desde la perspectiva del discurso del maestro y su práctica pedagógica, podríamos subrayar una contradicción entre lo que la maestra dice: "hay que enseñarlos a que ellos sean la excelencia, que pidan excelencia [ $¿ \mathrm{Tal}$ vez que confronten las verdades absolutas del contenido?], que trabajen con excelencia y que superen esas dificultades" y lo que en el aula, en último término, hace. Superficialmente, sería plausible afirmar que incurre en una contradicción como lo afirmo al principio, sin embargo, vale la pena resaltar, aunque no sea esto objeto de este escrito, lo siguiente: la maestra manifiesta, en primer lugar, según sus principios, querer obtener excelencia, calidad, nunca mediocridad, de allí el que exija, pero ¿exige? Por otra parte, parece ser que le da prioridad a la actividad que va a realizar, a su "labor"; el anhelar el éxito de su trabajo define la naturaleza de su práctica:

Profesora: yo de verdad le pido cada día a Dios me ilumine, porque esta labor es muy complicada, más en un medio de estos...

Aquí, cabe preguntarnos si el deseo de obtener excelencia, calidad es el único que direcciona su práctica pedagógica y no, por ejemplo, el de culminar cuanto antes su "labor", su ritual didáctico y continuar adelante con otras actividades. Esta gama de 


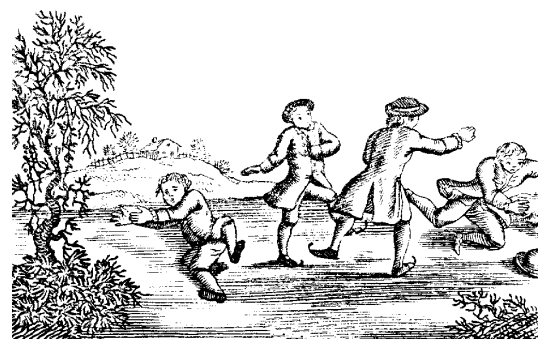

fines, no siempre explícitos, desde mi punto de vista, la impele a planear y controlar su clase de tal manera que las preguntas que formula y las explicaciones tan reiterativas que hace, por una parte, sean susceptibles de responder y repetir por cualquiera de los alumnos, sin temor a que se equivoquen, $y$, por otro lado, no den pie al surgimiento de posibles confrontaciones o preguntas que harían tambalear la verticalidad de su clase. Esto, sencillamente nos revela que el centro de su clase, no es propiamente el niño como podría pensarse, sino, el propósito de culminar, aparentemente con éxito su clase por "la simulación de apropiación"17 alcanzada en ésta, en la medida en que, los resultados obtenidos circunstancialmente [las reiteraciones de los estudiantes en correspondencia con su discurso] están en concordancia con su idea de "excelencia y calidad".

Finalmente, como corolario de este breve análisis, es preciso insistir, aunque de ello hablaré más concretamente en las con-

\footnotetext{
${ }^{17}$ Edwards, V. Los sujetos y la construcción social del conocimiento escolar en primaria: un estudio etnográfico, tesis de maestría, Departamento de Investigaciones Educativas, Centro de Investigación y de Estudios Avanzados del IPN, México. 1985, pág. 80.
}

clusiones, que, la configuración que prima en el aula en términos de estructuras de poder y relaciones sociales inciden en las intenciones de participación de los estudiantes, quienes optan por insertarse a la lógica de la actividad prescrita por la maestra en el aula a razón, por lo general, de la supervivencia escolar y académica que demandan, no tanto ellos como si la familia y la sociedad.

\section{CONCLUSIONES}

Hablar de 'para qué hablan los estudiantes', es muy distinto de hablar de 'para qué hablan los estudiantes en el aula de clase' si tenemos en cuenta que:

"Dentro de la vida institucional de la escuela, la situación social del aula constituye un encuentro ritualizado que se lleva a cabo de manera previsible y orgánica:

- Localización espacio-temporal: de lunes a viernes, en un horario preestablecido, durante un periodo académico fijado por las autoridades ministeriales, en lugar físico estable dentro de un establecimiento, donde se realizan otros encuentros similares y simultáneos.

- En el que participan, cara a cara, sujetos cuyos roles asimétricos se organizan en torno alas funciones de enseñar y aprender (es decir, se estipula como una relación de saber / poder con fines didácticos y de disciplinamiento);

- Y donde el intercambio verbal juega un papel preponderante" 18 .
La pregunta ¿para qué hablan los estudiantes en el aula? implica indudablemente reflexionar acerca de la influencia que el aula, como espacio escolar regulado, reglado, restrictivo y controlado, tiene sobre la comunicación maestro-alumno, ya que el lenguaje, según Elsa Ghio, "es el canal principal por el cual se trasmite y se aprende el conocimiento"1 9 .

Los estudiantes, por supuesto, hablan en el aula sobre diversos temas relacionados con su cotidianeidad pero saben, al igual que el maestro, que sólo ciertas disposiciones corporales y ciertos discursos son los que el aula, por el significado formal que reviste, legitima y acepta como válidos. De allí, "que no esperamos que los niños conviertan un entorno normal de clase en una cancha de baloncesto o en un W.C." 20 .

Los niños, por consiguiente, decodifican esa configuración discursiva y de poder que subyace en el aula y procuran, por lo general, adecuarse a la estructura social, política e instruccional que rige en el salón. Recordemos que "el aula está culturalmente pre-restringida por los límites establecidos por los roles sociales de las personas implicadas (adultos como enseñantes, niños como alumnos) para las

\footnotetext{
${ }^{18}$ Ghio,E.; Hechim, M.; Menendez, M. y otros. Decir, hacer y enseñar. Argentina: Universidad Nacional del Litoral. 1997, pág. 41.

19 lbid., pág. 41

${ }^{20}$ Coll, César y Derek, Edwards. Enseñanza, aprendizaje y discurso en el aula. Cap 2: Indeterminación restringida en los procesos del discurso, Jaan Valsiner. Aprendizaje S.L. Madrid, 1996, pág. 28.
} 
actividades de clase"21 incluso antes de ingresar al salón.

Esta percepción que poseen, tanto el maestro como los alumnos, del espacio educativo en el que interactúan corresponde a una pedagogía "visible"22, es decir, a un orden explícito en materia de normas, ritmos, lógicas, procedimientos y saberes, en donde los participantes del acto educativo asumen roles fuertemente caracterizados como maestros o como alumnos. Aquí, los discursos se encuentran demarcados de antemano según la naturaleza de los contenidos a tratar, lo cual, define en consecuencia el tipo y la lógica de la actividad que encausará la trasmisión de los contenidos en cuestión.

Por otra parte, la comunicación juega un papel fundamental en el espacio escolar al cual hago referencia, el aula. Si partimos de la idea de que "comunicarse es siempre entrar en el orden del discurso" en donde "se teje cotidianamente la espesa trama del poder social"23, es preciso reconocer y fortalecer los esfuerzos que los estudiantes hacen por intentar acceder al discurso que el maestro teje, así no sea con el fin de confrontarlo, hecho que brilla por su ausencia a causa de las condiciones sociales y estructuras de poder que comporta la escuela, sino, con el pro-

\footnotetext{
${ }^{21}$ lbid., pág. 28.

${ }^{22}$ Bernstein, B. 'Clases y pedagogías: visibles e invisibles". Revista Colombiana de Educación No. 15. 1985, págs. 73-103.

${ }^{23}$ Ghio,E.; Hechim, M.; Menendez, M. y otros. Decir, hacer y enseñar. Argentina: Universidad Nacional del Litoral. 1997, pág. 56.
}

pósito de negociar los significados de los contenidos en juego alrededor del discurso predominante, para luego, en un futuro, si es posible, subvertirlos a razón de una profunda aprehensión de los mismos.

Pero, si se desconoce el punto de vista, los cuestionamientos, la curiosidad y opiniones de los niños respecto de los contenidos que la maestra sólo expone y no pone en tela de juicio, obviando, no deliberadamente claro, la especificidad y comportamentalidad con la que da a conocer su contenido académico, sin advertir su complejidad en relación con otras áreas del saber y la vida, será muy difícil que los estudiantes accedan realmente al contenido y no solamente a la lógica de la actividad que propone la maestra y al "juego" de desciframientos, códigos, expectativas que de ella se deriva. Por esta razón, es preciso tener en cuenta que, "cuando se aprende, se incorporan los nuevos saberes a inclusores ya existentes en la estructura cognitiva de los sujetos, que operan como tamizadores o filtros de los saberes. De este modo, la significatividad en el aprendizaje es idiosincrática, ya que depende del sujeto que aprende"24. En otras palabras, los niños no son propiamente hojas en blanco, poseen un haber cultural donde compendian, en el transcurso de su existencia, múltiples experiencias e ideas que conjugan, en la medida de lo posible, y hasta donde el maestro se los permite, con los conte-

\footnotetext{
${ }^{24}$ Huergo, J . y Fernández, M. Cultura escolar, cultura mediática /intersecciones. Bogotá: Universidad Pedagógica Nacional. CACE. 1999. 183-184.
}

nidos científicos y normas que "aprenden" en el salón.

Fingir apropiarse de los contenidos es sencillo, afirmarán los estudiantes, de hecho, recuerdo como, después de finalizar el tema de las tildes y al dar de inmediato paso a otra actividad, los niños, al anotar los enunciados de las tareas correspondientes a la próxima clase, incurren en una serie de errores ortográficos que sólo dan cuenta de la pantomima que protagonizaron tanto maestros como estudiantes, ese día en el colegio, en relación con la apropiación de los contenidos académicos y no propiamente del conocimiento.

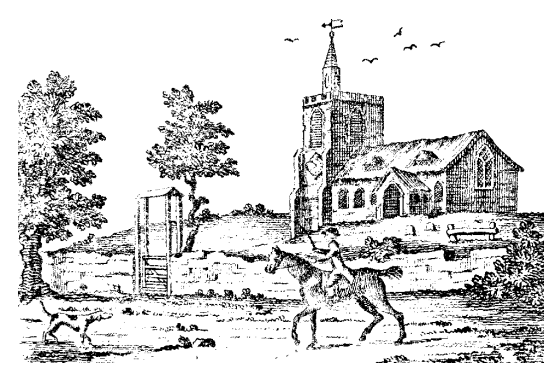

Conocimiento que, parece ser, reside en otras instancias diferentes a la escuela, en las cuales se crea y recrea a razón de la necesidad que implica para diferentes acciones y propósitos. En la escuela, a mi modo de ver, no es posible hablar de transmitir conocimiento, al menos no desde la perspectiva con la cual se asume el "conocimiento": contenidos, asignaturas, bloques, etc. El que los alumnos memoricen formulas, leyes, axiomas y respondan correctamente preguntas específicas, no necesariamente equivale a determinar 
que han logrado apropiarse de un "conocimiento", sólo lo han descrito y, en nuestro caso, ni siquiera empleado. Todo lo anterior conlleva y empieza a hacer visible una pregunta urgente con respecto a "qué entendemos por conocimiento", materia prima, aparentemente, de la escuela, ente que, desde mi punto de vista, constituye la antítesis del conocimiento pues, al prescindir de la curiosidad, la tensión, la incertidumbre, la pregunta y la confrontación; niega las condiciones originantes del conocimiento.

Como conclusión final, quisiera sólo apuntar lo siguiente: Los maestros, pese a que afirman reflexionar sobre su práctica pedagógica, ésta, finalmente, dista en gran medida de aquello que aseguran hacer. Su trabajo no es siempre objeto de análisis permanente y denodado, y ello ocurre, no porque adolezcan de buenas intenciones, sino, porque ellos, al igual que los estudiantes en relación con su rol, cumplen con su "deber de instruir al alumnado", y han interiorizado a tal punto dicho rol que cuando se equivocan, como afirma Guillermo Bustamante, "el maestro pierde la compostura, trata de enmendarse, haciéndose notar lo menos posible; y cuando sólo él se entera del error, por principio lo ocultará al alumno"25, por consiguiente, se hace evidente que nunca hubo comunicación y el maestro no toma distancia del fenómeno escolar sobre el cual, algún día espera reflexionar. Sin embargo, la culpa, si es que es

\footnotetext{
${ }^{25}$ Bustamente, G. "Maestro/alumno: una relación patológica". En: Revista Educación y Ciencia No. 4, Quinta Época, 1989.
}

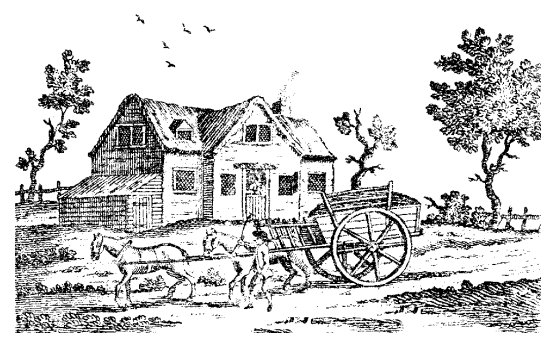

viable hablar de culpas, no es necesariamente de ellos; bien dijo al respecto Abel Rodríguez,: "los maestros no reflexionan sobre su práctica, por lo tanto, la producción de conocimientos de los maestros es muy poca, pero ¿por qué se ve eso?... lo que fueron las décadas de los 60, 70, 80 a los maestros se les trataba como unos administradores de unos currículos, los maestros cumplían un papel muy instrumental, entonces, nunca se planteó como lo planteó Piaget... el maestro como un INVESTIGADOR"26.

Es esta invitación, tal vez, que replantea Abel Rodríguez, el principal aporte de este trabajo. Situar la mirada de la investigación en el aula y en sus agentes. Investigar para educar y no educar para investigar. De hecho, es este mismo análisis un ejercicio de aproximación al ámbito de la investigación, pues, como bien lo sugiere Amanda Cortés con respecto a este trabajo, "hacer generalizaciones teniendo en cuenta que se observo sólo una clase, en un sólo momento y en un sólo espacio, podría ser riesgoso pues, acaso ¿podrían cambiar

\footnotetext{
${ }^{26}$ Entrevista concedida al grupo de proyecto en el marco del evento de "Expedición Pedagógica" 1999.
}

esas interpretaciones si se hubiera registrado otra clase de la misma maestra, otro día, con otro tema?"

Son muchas más las preguntas que suscita este estudio que las respuestas a las que hubiese podido dar lugar. Sin embargo, son precisamente esas tensiones relativas a los conceptos de comunicación, conocimiento, investigación, educación y poder que genera este trabajo, la riqueza que éste revela en relación con la extensa trayectoria que a partir de aquí, demandan los temas de educación e investigación.

\section{BIBLIOGRAFÍA}

Álvarez, A.; Rockwell, E. y otros. Hacia un currículo cultural. Rockwell, E. Cap. 1: La dinámica cultural en la escuela. España: Infancia y Aprendizaje. 1997, pág. 26.

Álvarez, A.; Rockwell, E. y otros. Hacia un currículo cultural. Rockwell, E. Cap. 1: La dinámica cultural en la escuela. España: Infancia y Aprendizaje, 1997, pág. 31.

Álvarez, A.; Rockwell, E. y otros. Hacia un currículo cultural. Rockwell, E. Cap. 1: La dinámica cultural en la escuela. España: Infancia y Aprendizaje. 1997, pág. 35.

Bernstein, B. "Clases y pedagogías: visibles e invisibles". Revista Colom-

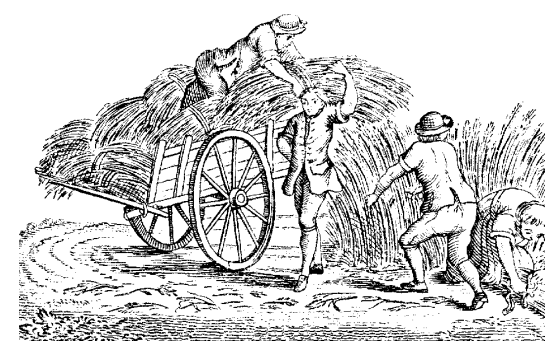


biana de Educación No. 15. 1985, págs. 73-103.

Bernstein, B. La estructura del discurso pedagógico. Ediciones Morata, 1994.

Bourdieu, Pierre. Sociología y cultura. México D.F.: Ed. Grijalbo, 1984, pág. 157.

Bustamente, G. "Maestro/alumno: una relación patológica". En: Revista Educación y Ciencia No. 4, Quinta Época, 1989.

Calvo, Beatriz; Ballesteros, G. y otros. Nuevos paradigmas, compromisos renovados. Cap. El análisis del discurso en el salón de clases. Klingler y Romero. México, Universidad autónoma de Ciudad Juárez, 1998, pág. 166.

Coll, César y Derek, Edwards. Enseñanza, aprendizaje y discurso en el aula. Cap. 2: Indeterminación restringida en los procesos del discurso, Jaan Valsiner. Madrid: Aprendizaje S.L.,1996, pág. 27.

Coll, César y Derek, Edwards. Enseñanza, aprendizaje y discurso en el aula. Cap 2: Indeterminación restringida en los procesos del discurso,
Jaan Valsiner. Aprendizaje S.L. Madrid, 1996, pág. 28.

EDWARDS, V. Los sujetos y la construcción social del conocimiento escolar en primaria: un estudio etnográfico, tesis de maestría, Departamento de Investigaciones Educativas, Centro de Investigación y de Estudios Avanzados del IPN, México. 1985, pág. 80.

GHIo,E.; HeChim, M.; MenéndeZ, M. y otros. Decir, hacer y enseñar. Argentina: Universidad Nacional del Litoral. 1997, pág. 77.

GHIo,E.; HeCHIM, M.; MenÉndeZ, M. y otros. Decir, hacer y enseñar. Argentina: Universidad Nacional del Litoral. 1997 pág. 41.

GHIo,E.; HeCHIM, M.; Menéndez, M. y otros. Decir, hacer y enseñar. Argentina: Universidad Nacional del Litoral. 1997, pág. 56.

GhIo,E.; HeCHIM, M.; MenÉndeZ, M. y otros. Decir, hacer y enseñar. Argentina: Universidad Nacional del Litoral. 1997 pág. 75 .

Heller, A. Sociología de la vida cotidiana. Madrid: Edit. Península. 1977, pág. 317.
Heller, A. Sociología de la vida cotidiana. Madrid: Edit. Península. 1977, pág. 20.

Huergo, J . y Fernández, M. Cultura escolar, cultura mediática /intersecciones. Bogotá: Universidad Pedagógica Nacional. CACE. 1999. 183-184.

Modelo instruccional de Mehan, 1979 Citado por KLINGER y Romero. Nuevos paradigmas; compromisos renovados. México: Universidad Autónoma de Juárez.1998, pág. 164.

Robison. Citado por Valsiner. Enseñanza, aprendizaje y discurso en el aula. Madrid: Aprendizaje S.L. 1996, pág. 136.

Rockwell, E. y Galvez, G. "Formas de transmisión del conocimiento científico, un análisis cualitativo". Educación: Revista del Consejo Nacional Técnico de la Educación, No. 42. México, 1982, págs. 97-139.

Entrevista concedida al grupo de proyecto en el marco del evento de "Expedición Pedagógica", 1999. 